CLIMATIC CHANGE AND ITS IMPACTS 


\section{ADVANCES IN GLOBAL CHANGE RESEARCH}

\section{VOLUME 19}

\section{Editor-in-Chief}

Martin Beniston, Department of Geosciences, University of Fribourg, Switzerland

\section{Editorial Advisory Board}

B. Allen-Diaz, Department ESPM-Ecosystem Sciences, University of California, Berkeley, CA, U.S.A.

R.S. Bradley, Department of Geosciences, University of Massachusetts, Amherst, MA, U.S.A.

W. Cramer, Department of Global Change and Natural Systems, Potsdam Institute for Climate Impact Research, Potsdam, Germany.

H.F. Diaz, Climate Diagnostics Center, Oceanic and Atmospheric Research, NOAA, Boulder, CO, U.S.A.

S. Erkman, Institute for Communication and Analysis of Science and Technology - ICAST, Geneva, Switzerland.

R. García Herrera, Facultad de Físicas, Universidad Complutense, Madrid, Spain

M. Lal, Centre for Atmospheric Sciences, Indian Institute of Technology, New Delhi, India.

U. Luterbacher, The Graduate Institute of International Studies, University of Geneva, Geneva, Switzerland.

I. Noble, CRC for Greenhouse Accounting and Research School of Biological Sciences, Australian National University, Canberra, Australia.

L. Tessier, Institut Mediterranéen d'Ecologie et Paléoécologie, Marseille, France.

F. Toth, International Institute for Applied Systems Analysis, Laxenburg, Austria.

M.M. Verstraete, Institute for Environment and Sustainability, EC Joint Research Centre, Ispra (VA), Italy. 


\title{
CLIMATIC CHANGE AND ITS IMPACTS
}

An Overview Focusing on Switzerland

\author{
by \\ Martin Beniston \\ Department of Geosciences, \\ University of Fribourg, Switzerland
}

KLUWER ACADEMIC PUBLISHERS

DORDRECHT / BOSTON / LONDON 
A C.I.P. Catalogue record for this book is available from the Library of Congress.

ISBN 978-90-481-6643-5

DOI 10.1007/978-1-4020-2346-0

ISBN 978-1-4020-2346-0 (eBook)

Published by Kluwer Academic Publishers,

P.O. Box 17, 3300 AA Dordrecht, The Netherlands.

Sold and distributed in North, Central and South America

by Kluwer Academic Publishers,

101 Philip Drive, Norwell, MA 02061, U.S.A.

In all other countries, sold and distributed

by Kluwer Academic Publishers,

P.O. Box 322, 3300 AH Dordrecht, The Netherlands.

Printed on acid-free paper

All Rights Reserved

(C) 2004 Kluwer Academic Publishers and copyright holders

Softcover reprint of the hardcover 1 st edition 2004 as specified on appropriate pages within.

No part of this work may be reproduced, stored in a retrieval system, or transmitted in any form or by any means, electronic, mechanical, photocopying, microfilming, recording or otherwise, without written permission from the Publisher, with the exception of any material supplied specifically for the purpose of being entered and executed on a computer system, for exclusive use by the purchaser of the work. 


\section{Table of contents}

Foreword

ix

1 Climate, the environment, and humankind:

lessons from the past

1.1 Introduction

1.2 Population migrations in the past

1.3 Population migrations in the $20^{\text {th }}$ century 10

1.4 Possible environmental change and population

migrations in the $21^{\text {st }}$ century

13

$\begin{array}{ll}\text { 1.4.1 Preamble } & 13\end{array}$

$\begin{array}{ll}\text { 1.4.2 Water resources } & 14\end{array}$

1.4.3 Food security $\quad 17$

1.4.4 Health: the particular case of malaria $\quad 20$

1.5 Conclusions to Chapter $1 \quad 24$

2 The climate system $\quad 27$

2.1 Energy for the system $\quad 27$

2.2 Heat transport from Equator to Pole 36

2.3 Elements of the climate system $\quad 40$

2.3.1 The atmosphere $\quad 41$

2.3.2 The oceans 43

2.3.3 The cryosphere 45

2.3.4 Water and the hydrological cycle $\quad 47$

2.3.5 The biosphere $\quad 48$

2.3.6 The lithosphere $\quad 51$

3 Natural forcing of the climate system 53

3.1 External forcing of climate 53

3.1.1 The astronomic forcing of climate 53

3.1.2 Solar cycles $\quad 57$

3.2 Internal forcing of climate $\quad 59$

3.2.1 Volcanic activity $\quad 59$

3.2.2 Ocean-atmosphere feedbacks; El Niño/Southern 
3.2.3 Low frequency climate variability: the North Atlantic Oscillation

\section{Anthropogenic forcing of the climate system}

4.1 Human interference with the climate system 73

4.2 The global carbon cycle $\quad 74$

4.3 The global energy system $\quad 78$

4.4 Characteristics of greenhouse gases $\quad 84$

4.5 Future trends in greenhouse gas emissions $\quad 88$

5 Modeling and observing climate $\quad 91$

5.1 Introduction 91

5.2 Energy balance models $\quad 92$

5.3 Atmospheric general circulation models: equations and parameterizations $\quad 98$

5.3.1 Radiation 103

5.3.2 Clouds and precipitation $\quad 104$

5.3.3 Subgrid-scale turbulent transport 106

$\begin{array}{ll}\text { 5.3.4 Gravity wave drag } & 109\end{array}$

5.3.5 Land-surface processes $\quad 110$

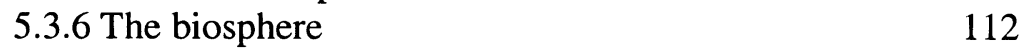

5.3.7 The cryosphere $\quad 113$

5.4 Coupled model systems $\quad 114$

5.5 Boundary conditions, validation, and range of

5.6 Chaos in the system? 118

5.7 Observing and monitoring climate 121

6 Current and future climatic change 129

6.1 Evidence for climatic change and the emergence $\begin{array}{ll}\text { of the anthropogenic factor } & 129\end{array}$

6.2 Projections of future change at the global scale 138

6.3 Regional climate models: linking the global and the regional scales 
6.4 Projections of future change at the regional scale:

Application to Europe

7 Climate in Switzerland since 1900

7.1 Introduction

7.2 Particularities of alpine climate

7.3 Observed changes in climate in Switzerland

7.3.1 Trends in mean, minimum and maximum temperatures

7.3.2 Links between climatic features in Switzerland and the behavior of the North Atlantic Oscillation

7.3.3 Changes in extreme weather events

7.3.4 The 2003 heat wave

8 Climate trends and impacts in Switzerland in the $21^{\text {st }}$ century

8.1 Estimates of changes in means and extremes in Switzerland

8.2 Impacts on the alpine environment

8.2.1 Issues related to impacts assessments

8.2.2 Impacts on alpine snow cover

8.2.3 Impacts on alpine glaciers

8.2.4 Impacts on hydrological regimes and associated natural hazards

8.2.5 Impacts on alpine vegetation

8.3 Impacts on socio-economic sectors

9.1 Addressing climatic change

9.2 The Kyoto Protocol

9.3 Interpretation and implications of articles of the

Framework Convention

9.4 The role of science 


\section{Foreword}

Climatic change is a rapidly evolving domain that has prompted the publication of numerous scientific works in recent years. These publications reflect both the public and scientific interest in the topic, as well as the progress in science that observation and modeling has allowed since concerns were raised about the human influence on climate in the last quarter of the $20^{\text {th }}$ century.

This book provides an overview of climate processes, variability and change and applies the general principles related to these issues to the particular case of Switzerland. Although a small country, Switzerland is located in a region of complex topography where climate processes can often be of a very dynamic nature due to the presence of the Alps. Indeed, monitoring of climate in mountains may enable the early detection of the anthropogenic climate signal more readily than other regions, particularly those where urbanization or low-level boundary-layer processes can contaminate data and thereby lead to difficulties in disaggregating different signals in the record. In addition, there is a remarkable density of observational data in Switzerland, ranging from climate, ecology, and landuse, to socio-economic statistics. Access to high quality data enables a comprehensive assessment of climate processes and their long-term trends, comparisons of modeling techniques with real-world data, and environmental and socio-economic investigations of the impacts of climatic change on the natural, social, and economic environments.

This book principally draws upon recent scientific work by the author, based on research conducted within scientific networks both in Switzerland and Europe. It contains in a single volume an overview of the fundamentals of climate, methods of observation and modeling of the climate system, and applications of these basic concepts and paradigms to the particular case of Switzerland. The focus on the alpine region serves to highlight regional climatic change at low, medium, and high-elevation sites as observed over the past 100 years, and the latest climate model data enables a look into coming decades as climate responds to increasing concentrations of greenhouse gases in the atmosphere. Consideration is given to shifts in mean climate and extremes in the $20^{\text {th }}$ century and the latter part of the $21^{\text {st }}$ 
century, and to the impacts of expected change on the alpine cryosphere, hydrology, and vegetation as well as on certain managed systems such as agriculture, energy supply and tourism.

The book is aimed primarily at an academic audience from the graduate level and beyond, but may attract the interest of the general public as it strives to strike a balance between descriptive and technical aspects related to the diverse topics that are addressed. The monograph is a contribution to international efforts aimed at furthering the understanding of the intricacies of climate at local and regional scales, and the consequences of regional climatic change on the alpine domain. 